\title{
2019 EULAR recommendations for the generic core competences of health professionals in rheumatology
}

\author{
Lisa Edelaar, ${ }^{1,2}$ Elena Nikiphorou (D) ,' George E Fragoulis (1) , ${ }^{4}$ Annamaria lagnocco, ${ }^{5}$ \\ Catherine Haines, ${ }^{6,7}$ Margot Bakkers, ${ }^{8}$ Lurdes Barbosa (D) , ${ }^{9}$ Nada Cikes, ${ }^{10}$ \\ Mwidimi Ndosi (1D) ,' Jette Primdahl (D) ${ }^{12,13}$ Yeliz Prior, ${ }^{14,15}$ Polina Pchelnikova, ${ }^{8}$ \\ Valentin Ritschl, ${ }^{16,17}$ Valentin Sebastian Schäfer (D) , ${ }^{18}$ Hana Smucrova (D) , ${ }^{19}$ \\ Inger Storrønning, ${ }^{20}$ Marco Testa, $^{21}$ Dieter Wiek, $^{8}$ Theodora P M Vliet Vlieland (D) $^{1}$
}

\begin{abstract}
Handling editor Josef $S$ Smolen

- Additional material is published online only. To view please visit the journal online (http://dx.doi.org/10.1136/ annrheumdis-2019-215803)

For numbered affiliations see end of article.
\end{abstract}

Correspondence to Professor Theodora P M Vliet Vlieland, Orthopaedics, Rehabilitation and Physical Therapy, J11, Leiden University Medical Center, Leiden 2333

ZA, The Netherlands; T.P.M.Vliet_Vlieland@lumc.nl

Received 29 May 2019 Revised 25 July 2019 Accepted 26 July 2019 Published Online First 9 August 2019

\section{Check for updates}

(C) Author(s) (or their employer(s)) 2020. No commercial re-use. See rights and permissions. Published by BMJ.

To cite: Edelaar L, Nikiphorou E, Fragoulis GE, et al. Ann Rheum Dis 2020;79:53-60.

\section{ABSTRACT}

Background/objectives To maintain and optimise the quality of care provided by health professionals in rheumatology (HPRs), adequate educational offerings are needed. This task force (TF) aimed to develop evidence-based recommendations for the generic core competences of HPRs, with specific reference to nurses, physical therapists (PTs) and occupational therapists (OTs) to serve as a basis for their postgraduate education.

\section{Methods The EULAR standardised operating} procedures for the development of recommendations were followed. A TF including rheumatologists, nurses, PTs, OTs, patient-representatives, an educationalist, methodologists and researchers from 12 countries met twice. In the first TF meeting, 13 research questions were defined to support a systematic literature review (SLR). In the second meeting, the SLR evidence was discussed and recommendations formulated. Subsequently, level of evidence and strength of recommendation were assigned and level of agreement (LOA) determined (0-10 rating scale).

Results Three overarching principles were identified and 10 recommendations were developed for the generic core competences of HPRs. The SLR included 79 full-text papers, 20 of which addressed the competences, knowledge, skills, attitudes and/or educational needs of HPRs from multiple professions. The average LoA for each recommendation ranged from 9.42 to 9.79 . Consensus was reached both on a research and educational agenda. Conclusion Evidence and expert opinion informed a set of recommendations providing guidance on the generic core competences of HPRs. Implementation of these recommendations in the postgraduate education of HPRs at the international and national level is advised, considering variation in healthcare systems and professional roles.

\section{INTRODUCTION}

Health professionals in rheumatology (HPRs) play an important role in the care of people with rheumatic and musculoskeletal diseases (RMDs). Up-todate knowledge and relevant skills are essential to provide safe and effective patient care. Although multiple educational offerings have been developed for HPRs at postgraduate level, their availability and content vary largely among countries as well as by profession. ${ }^{1}$ It is imperative that the definition or development of a curriculum for HPRs, that is harmonised across countries, has international consensus on the core competences needed for the management of people with RMDs.

A set of desirable competences already exists at European level for rheumatologists. ${ }^{2}$ For HPRs, relevant work has been done only at national level. In the UK, a Delphi-based study identified the core competences that non-specialist communitybased nurses and allied HPRs should have. ${ }^{3}$ Also, the Health Education England, NHS England and Skills for Health recently published the musculoskeletal core capabilities framework for a range of practitioners in rheumatology who act as first point reference. ${ }^{4}$ Currently, no such sets of generic competences HPRs of multiple professions have in common exist at European level.

To address this unmet need, a EULAR task force (TF) was set up to develop EULAR-endorsed recommendations for generic core competences of HPRs of multiple professions at the postgraduate level. These would need to constitute the common base of competences every HPR working with people with RMDs should have. On top of that, HPRs may need additional competences, depending on their specific profession. Although it was considered that HPRs represent a broad range of professions, the project focused on nurses, physical therapists (PTs) and occupational therapists (OTs). These professionals were, apart from physicians, considered to be most frequently involved in the care of people with RMDs. The EULAR recommendations for the generic core competences of HPRs are intended for all HPRs and other healthcare providers in the field of RMDs and are relevant to key stakeholders that is, patients, as well as their (inter)national organisations; institutions and clinical educators providing education for HPRs. Furthermore, these recommendations could serve as a framework for all relevant stakeholders other than just service providers, including health insurers and policy makers as well as a reference document for generic competences of health professionals in other specialties.

\section{METHODS}

The updated EULAR standardised operating procedures (SOPs) for the development of the recommendations were followed ${ }^{5}$ after approval of the TF by the EULAR Executive Committee. The multidisciplinary TF comprised of a selection of nine experts in HPRs' education (three nurses, two PTs, three 
OTs, one rheumatologist), two EMEUNET members (VS, GF), three patient representatives and a steering group managing the process (convenors TVV and AI, methodologists EN and TVV, educationalist $\mathrm{CH}$, fellows LE and GF). There was broad country representation in the TF from across 12 countries (Netherlands, Italy, UK, Portugal, Denmark, Norway, Czech Republic, Austria, Croatia, Germany, Russia, Greece).

During the first TF meeting, definitions of competences and a clear definition of HPRs were agreed. Clinically relevant questions on HPRs' education, skills and practice were discussed, and research questions were defined by consensus to form the basis for the subsequent systematic literature review (SLR). The literature on the competences, roles, knowledge, attitudes, skills or educational needs of HPRs in general, or specifically for nurses, PTs or OTs and at postgraduate level was systematically identified using a structured search strategy in multiple electronic databases (PubMed/Medline, Embase, Cochrane library, CENTRAL, Emcare, PsycINFO, Academic Search Premier, Web of Science, Google Scholar and the educational databases ERIC and National Science Digital Library). National presidents or liaison persons of HPRs' organisations were also contacted to supplement the information retrieved from the SLR. Details of the search strategy, including study selection, data extraction and data synthesis are provided in a separate manuscript (under submission). Studies addressing competences of multiple HPRs (including nurses and/or PTs and/or OTs) were considered as the most appropriate to answer the research questions. Methodological quality of each of the studies addressing competences of HPRs of multiple professions was scored (LE, GF, EN) using appropriate tools $^{6-8}$ (see details in online supplementary table S1). Studies describing competences of a single profession (nurse, PT or OT) were only used to confirm the generic core competences as derived from the literature addressing generic competences of HPRs of multiple professions. If more specific information and relevant details in support of generic competences was provided in the literature addressing a single profession, that information was extracted. Competences that unambiguously can or should only be applied or performed by one profession were not taken into account, with the distinction being based on professional profiles and one of the studies providing a detailed description of desired competences per discipline. ${ }^{9}$

The findings of the SLR were presented by the fellows at the second TF meeting and formed the basis of a detailed discussion by the TF that informed the wording of overarching principles (OAPs) and recommendations. The OAPs/recommendations were voted on informally by the TF and if at least $75 \%$ approved each OAP and recommendation, these were accepted. If not, discussion was resumed with changes proposed followed by further rounds and was completed if the vote indicated the majority approved the $\mathrm{OAP} /$ recommendations. At the second TF meeting, a brief discussion on the educational and research agenda was also commenced, subsequently completed by email communication with all TF members.

After the second meeting, the level of evidence (LoE) and strength of the recommendation (SoR) were determined by the steering group. The LoE was determined separately for qualitative and quantitative studies using appropriate tools, both rated on a scale from 1 to 4 . For the categorisation of the LoE from quantitative papers, the Oxford levels of evidence was used, as described in the EULAR SOP. ${ }^{10}$ The LoE for qualitative papers was categorised using a modified version of the hierarchy of evidence-for-practice in qualitative research by Daly et al, ${ }^{11}$ with subcategories (a and b) added at each level to allow for more accurate reflection of grading of the evidence based on studies falling between two levels due to their type and employed methodology. In brief, the hierarchy of evidence in qualitative research-study types suggested by Daly et $a l^{11}$ proposes a four-level hierarchy of the quality of evidence for practice. The highest level (level I) refers to generalisable studies, level II to conceptual studies, level III to descriptive studies and level IV to single case studies. To assign a specific LoE, the number of studies available for each category was taken into account, similar to the Oxford levels of evidence. ${ }^{10}$ The SoRs was determined based on discussions within the TF including a comprehensive process of weighting the LoE in the context of the impact of the paper, evidence for practice, its quality, applicability and validity, as well as the type of study and its determined hierarchical LoE. ${ }^{11}$

The final recommendations including the LoE and SoR were then circulated by e-mail to all TF members to provide the level of agreement (LoA) independently and anonymously on a $0-10$ numeric rating scale $(0=$ completely disagree, $10=$ completely agree). The mean, SD, median and range of the LoA per recommendation, were presented. Moreover, TF members were independently asked for any further input on the research and educational agenda by e-mail. Draft research and educational agendas were circulated based on suggestions from the second TF meeting and revised by the steering group based on the e-mail responses.

\section{RESULTS}

At the first TF meeting, competences of HPRs were in general defined as "A set of knowledge, skills and attitudes that concern the consistent and appropriate use of communication, knowledge, skills, clinical reasoning, emotions, values and reflection on practice, for the benefit of people with RMDs and the community". For HPRs a definition used by EULAR was employed: "A professional involved in the care of people with RMDs, who is not a registered medical practitioner and is eligible to be a member of the organization through which a country has become a EULAR HP member". Furthermore, agreement on 13 main themes, translated into research questions (see online supplementary table S2) was achieved and subsequently formed the basis of the SLR (see separate manuscript). In total, 79 papers were included; 20 addressed the competences HPRs of multiple professions have in common, ${ }^{134912-27} 43$ the competences of nurses, ${ }^{28-70} 12$ of PTs ${ }^{71-82}$ and four of OTs. ${ }^{83-86}$ From the 20 papers addressing the competences HPRs of multiple professions have in common, $75 \%(n=15)$ had a qualitative design. ${ }^{13} 491213151618-202325-27$ The rest consisted of two systematic reviews, ${ }^{11} 21$ one quantitative study, ${ }^{14}$ one mixed design study ${ }^{9}$ and one opinion paper. ${ }^{19}$ Quality scoring of each of these papers revealed half of them $(n=10)$ to be of high quality, five of medium/moderate quality, three of low quality, one of critically low quality. One paper was not scored (opinion paper).

Overall, the evidence for the OAPs and recommendations was derived from the papers addressing the competences of HPR of multiple professions. ${ }^{134912-27}$ The evidence was supported by studies describing the desired competences of specific professions. $^{28-86}$

At the second TF meeting three OAPs and 10 recommendations were formulated. For all three OAPs and the recommendations a high LoE was determined (level I or II). ${ }^{11}$ Regarding the SoR, five recommendations were graded as strength level A, four as strength $\mathrm{B}$ and one as strength $\mathrm{B} / \mathrm{C}$. The average LoA for each recommendation ranged from 9.42 to 9.79 . Table 1 summarises the OAPs and recommendations with their associated LoE, SoR and LoA. 
Table 1 Overarching principles and recommendations for the generic core competences of health professionals in rheumatology (HPRs)

Level of agreement

Level of Strength of $\quad$ Mean (SD)

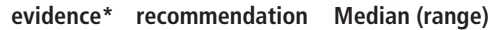

\section{Overarching principles}

A. Effective communication skills and a biopsychosocial approach in the assessment, treatment and care of people with RMDs are of paramount importance for HPRs

B. Person-centred care and patient advocacy are fundamental in the care delivered by HPRs for people with RMDs

\begin{tabular}{|c|c|c|}
\hline${ }_{\mathrm{QL}} \mathrm{lb}$ & NA & $\begin{array}{l}9.79(0.71) \\
10(7-10)\end{array}$ \\
\hline QL la & NA & $\begin{array}{l}9.74(0.65) \\
10(8-10)\end{array}$ \\
\hline${ }_{\mathrm{QL}}{ }^{\mathrm{llb}}$ & NA & $\begin{array}{l}9.68(0.75) \\
10(7-10)\end{array}$ \\
\hline${ }_{\mathrm{Q}}{ }_{\mathrm{lb}}$ & $A$ & $\begin{array}{l}9.42(1.07) \\
10(7-10)\end{array}$ \\
\hline QL & B & $\begin{array}{l}9.68(0.58) \\
10(8-10)\end{array}$ \\
\hline QL lla & $\mathrm{B} / \mathrm{C}$ & $\begin{array}{l}9.74(0.73) \\
10(7-10)\end{array}$ \\
\hline
\end{tabular}

C. An evidence-based approach, ethical conduct and reflective practice are essential for HPRs

Recommendations

1. HPRs should have knowledge of the aetiology, pathophysiology, epidemiology, clinical features and diagnostic procedures of common QL

RMDs, including their impact on all aspects of life

2. Using a structured assessment, HPRs should identify aspects that may influence individuals with RMDs and their families, including:

- Clinical characteristics, risks, red flags and comorbidities.

$10(7-10)$

3. HPRs should communicate effectively:

- To make contributions to other healthcare providers and stakeholders in RMD care.

4. HPRs should have an understanding of common pharmacological and surgical therapies in RMDs, including their anticipated benefits, side-effects and risks, and use this knowledge to advise or refer as appropriate

5. HPRs should provide advice on non-pharmacological interventions, treat or refer as appropriate, based on the evidence, expected benefits, limitations and risks for people with RMDs

6. HPRs should assess the educational needs of people with RMDs and their carers to provide tailored education using appropriate modes of delivery, relevant resources and evaluate their effectiveness

7. HPRs should take responsibility for their continuous learning and ongoing professional development to remain up-to-date with the clinical guidelines and/or recommendations on the management of RMDs

8. HPRs should support people with RMDs in goal setting and shared decision making about their care (eg, identify, prioritise, address their needs and preferences and explain in lay terms)

9. HPRs should support people with RMDs in self-management of their condition. This encompasses selecting and applying the appropriate behavioural approaches and techniques to optimise their health and well-being (eg, engagement in physical activity, pain and fatigue management)

10. HPRs should be able to select and apply outcome measures for people with RMDs, as appropriate, to evaluate the effectiveness of their interventions

\begin{tabular}{|c|c|c|}
\hline${ }_{\mathrm{QL}}{ }^{\mathrm{lb}}$ & B & $\begin{array}{l}9.47(0.84) \\
10(8-10)\end{array}$ \\
\hline${ }_{\mathrm{QL}} \mathrm{lb}$ & B & $\begin{array}{l}9.53(0.90) \\
10(7-10)\end{array}$ \\
\hline${ }_{\mathrm{QL}} \mathrm{lb}$ & A & $\begin{array}{l}9.42(1.02) \\
10(6-10)\end{array}$ \\
\hline QL ${ }^{l b}$ & A & $\begin{array}{l}9.79(0.71) \\
10(7-10)\end{array}$ \\
\hline${ }_{\text {QL }}$ lla & B & $\begin{array}{l}9.42(1.07) \\
10(6-10)\end{array}$ \\
\hline${ }_{\mathrm{QL}} \mathrm{lb}$ & A & $\begin{array}{l}9.74(0.81) \\
10(7-10)\end{array}$ \\
\hline${ }_{\mathrm{Q}} \mathrm{lb}$ & A & $\begin{array}{l}9.74(0.73) \\
10(7-10)\end{array}$ \\
\hline
\end{tabular}

ql Indicates a LoE based on studies that used primarily qualitative methods.

*Level of evidence from qualitative studies indicated for OAPs and recommendations for completeness.

LoE, level of evidence; NA, Not Applicable; OAPs, overarching principles; RMDs, rheumatic and musculoskeletal diseases.

\section{Overarching principles}

Table 2 presents the OAP along with the supporting literature.

Recommendation 1: HPRs should have knowledge of the aetiology, pathophysiology, epidemiology, clinical features and diagnostic procedures of common RMDs, including their impact on all aspects of life

HPRs should have updated knowledge of the normal structure and function and the pathophysiology of the musculoskeletal system; common pathophysiological processes to support diagnosis and management of RMDs; and the epidemiology, clinical features and diagnostic procedures of common RMDs. ${ }^{134923}$ This knowledge should include the prognosis and progression of RMDs. ${ }^{23}$ It is stressed in particular that HPRs should be able to understand and distinguish between inflammatory arthritis (IA) and osteoarthritis (OA) ${ }^{16}$ Finally, evidence supports that HPRs should have knowledge on the impact of RMDs on all aspects of life, that is, all components

Table 2 Overarching principles of the EULAR recommendations for the generic core competences of health professionals in rheumatology (HPRs)

Overarching principle 1 :

Effective communication skills and a biopsychosocial approach in the assessment, treatment and with with RMDs are of paramount importance for HPRs

Overarching principle 2:

Person-centred care and patient advocacy are fundamental in the care delivered by HPRs for people with RMDs

Overarching principle 3 : An evidence-based approach, ethical conduct and reflective practice are essential for HPRs
HPRs should be able to understand the interplay between RMDs and various personal and environmental factors, in the context of the biopsychosocial model. ${ }^{3413162021}$ The literature underpins the general principle that understanding and applying the principles of the biopsychosocial model is considered mandatory for the employment of a holistic approach. ${ }^{413}$ Two studies reported that a basic understanding of the International Classification of Functioning, Disability and Health could serve this purpose. ${ }^{1621}$ Another key element concerns communication, not only for effective interaction with patients but also with other healthcare providers, their organisations or other stakeholders ${ }^{3413}$

HPRs should respect individuality and take into account how background, experiences and values might affect patients' perceptions about their condition and its impact on their lives. ${ }^{34}$ It should in particular be noted that the experience and expertise of persons with an RMD about how to manage their disease, especially those who have a diagnosis for a long time, should not be disregarded. ${ }^{313}$ Advocacy not only concerns serving as an advocate for individual patients, but for groups or populations of people with RMDs as well by working in partnerships with teams, communities and organisations ${ }^{4}$

Captured in the framework of a national health-system for the core capabilities of professionals working with people with RMDs ${ }^{3}$ the care provided by HPRs should adhere to the evidence-based data for best practice and outcome. ${ }^{23}$ HPRs are expected to provide standardised care in accordance with national and International regulations, professional codes and employer protocols. ${ }^{316} 18$ The literature also suggests that HPRs should act towards development, organisation and advocacy of their group. ${ }^{1916}$ To monitor and improve the quality of care delivered, appropriate assessment of the services provided is needed. ${ }^{39}$ To that end, HPRs should be familiar with the principles of reflecting on their practice. ${ }^{3}$ Apart from an evidence-based approach and reflective practice, acting in an ethical manner is appraised as one of the cornerstones in HPRs' work ${ }^{316}$ 
of the International Classification of Functioning, Disability and Health (ICF). ${ }^{9} 3$

Recommendation 2: Using a structured assessment, HPRs should identify aspects that may influence individuals with RMDs and their families, including: (a) clinical characteristics, risks, red flags and comorbidities, (b) limits to their activity and participation and (c) personal and environmental factors

There is substantial evidence on HPRs' competences regarding the performance of a structured and comprehensive assessment. ${ }^{1} 349141617$ 20-23 25 Such a structured, comprehensive assessment is needed to understand the impact of the RMD on the individual; not only on his or her physical or mental health but also on relationships with family and friends, and on societal participation. ${ }^{34916}$ For that purpose, the assessment should be based on a biopsychosocial model. ${ }^{3413162021}$ Two studies reported that a basic understanding of the ICF could serve this purpose $^{1621}$ (see Overarching Principle 1). The structured assessment includes an exploration of the individuals' perceptions, concerns, ideas or beliefs about their symptoms and condition, as these may act as a driver or form a barrier to recovery or a return to usual activity or work. ${ }^{420}$ Apart from history taking, the assessment may consist of physical examination and interpretation of findings from additional examinations. Based on the results of the assessment, HPRs should use their clinical reasoning skills to interpret findings, develop working and differential diagnoses, formulate, communicate, implement and evaluate management plans. ${ }^{4}$

Recommendation 3: HPRs should communicate effectively: to make contributions to other healthcare providers and stakeholders in RMD care and to collaborate with other healthcare providers, signpost or refer where appropriate to optimise the interdisciplinary care of people with RMDs

Collaboration in the multidisciplinary team is important to optimise care for people with RMDs and to make appropriate referrals according to the HPR literature. ${ }^{34162226}$ For this purpose, HPRs must understand, respect and draw on each other's roles and competences. ${ }^{3} 421$ The literature highlights that effective communication includes explaining and advising people with RMDs about the importance of relevant healthcare professionals and organisations such as patient organisations. ${ }^{92023}$

Recommendation 4: HPRs should have an understanding of common pharmacological and surgical therapies in RMDs, including their anticipated benefits, side-effects and risks, and use this knowledge to advise or refer as appropriate

HPRs should have a broad knowledge and understanding on how to give advice on the use of drug treatment in RMDs 13491623 and have knowledge on the most common and/or serious side effects of specific drugs. This includes simple analgesics, nonsteroidal anti-inflammatory drugs, glucocorticoids; diseasemodifying antirheumatic drugs (DMARDS, that is, conventional synthetic DMARDs, targeted synthetic DMARDs and biological DMARDs) and other drugs used in treating patients with IA and other RMDs and in the management of persistent pain. Responses to medication should be reviewed regularly with the patient, taking into account patients' fears, beliefs and concerns, in order to recognise differences in the balance of risks and benefits. ${ }^{4}$ For joint injections, HPRs should understand the role of joint injections in the management of RMDs, and, how to advice on the expected benefits and limitations, and, refer as appropriate. ${ }^{4}$ Additionally, HPRs are expected to have knowledge about common surgical interventions in RMDs like OA and IA. They should be able to discuss with patients their fears and concerns regarding surgery, and able to provide advice about potential risks and benefits to support patient education. ${ }^{34}$

Recommendation 5: HPRs should provide advice on nonpharmacological interventions, treat or refer as appropriate, based on the evidence, expected benefits, limitations and risks for people with RMDs

There is evidence suggesting that HPRs should understand the role of and provide advice on non-pharmacological interventions, treat or refer as appropriate, based on the evidence, expected benefits, limitations and risks for people with RMDs. ${ }^{1349162328}$ Planning and implementation of non-pharmacological treatment should be done in collaboration with the patient and the multidisciplinary team (see also recommendation 3). Furthermore, HPRs should work with patients to alleviate their concerns about treatment, with an understanding that some people with RMDs (eg, patients with mental health conditions, multimorbidity, fatigue or frailty) might need additional support during rehabilitation and that their trajectory of recovery or increased independence may be slower than others. ${ }^{4}$ Addressing fitness to work in people with RMDs was also highlighted in the literature. ${ }^{4}$

Recommendation 6: HPRs should assess the educational needs of people with RMDs and their carers to provide tailored education using appropriate modes of delivery, relevant resources and evaluate their effectiveness

HPRs should be able to assess the educational needs of patients and provide a tailored education based on the patient's individual needs and characteristics. ${ }^{22} 27$ The provision of tailored education for patients with RMDs and their carers should be based on a theoretical framework ${ }^{24}$ and include the use of appropriate modes of delivery (eg, face-to-face individual or group, through websites, e-mail or social media), relevant resources and evaluation of its effectiveness. ${ }^{3} 9121620232627$ HPRs should be able to signpost to sources of education and information 31620 (see recommendation 3). The content of the education should be carefully checked for its evidence-base. ${ }^{24}$ Moreover, the importance of the promotion of a healthy lifestyle, in particular physical activity education, diet and nutrition, or smoking cessation, was underlined in multiple papers. ${ }^{4} 91319$

Recommendation 7: HPRs should take responsibility for their continuous learning and ongoing professional development to remain up-to-date with the clinical guidelines and/or recommendations on the management of RMDs

HPRs should continuously undertake professional development and remain up-to-date with the best available evidence. ${ }^{49} 2627$ This can be achieved through organised and accredited educational courses, implementation of clinical guidelines, research findings and/or recommendations on the management of RMDs. ${ }^{4} 926$

Regarding professional development, one of the studies concludes that HPRs should be minimally able to critically evaluate research evidence (eg, scientific papers), apply results from research into daily practice, and, identify and formulate relevant research questions. ${ }^{9}$ In addition HPRs should enable and participate (leading or contributing, as appropriate) in research to advance the development of knowledge on RMDs and practice. $^{49}$ 
Recommendation 8: HPRs should support people with RMDs in goal setting and shared decision making about their care (eg, identify, prioritise, address their needs and preferences and explain in lay terms)

Evidence for required HPRs' competences to support people with RMDs in goal setting and shared decision making to facilitate the delivery of patient-centred care is noteworthy. ${ }^{4} 91520$

Regarding goal setting, the literature provides evidence that HPRs should be able to set intervention goals related to his or her own profession; the formulation of these goals should be SMART (Specific, Measurable, Attainable, Realistic, Timely). ${ }^{9}$ Support with shared decision making may consist of helping people with RMDs to identify the priorities and outcomes that are important to them, explaining in non-technical language all available options, exploring with them the risks, benefits and consequences of each available option and discussing what these mean in the context of their life and goals and supporting them to make a decision on their preferred way forward. ${ }^{4}$

Recommendation 9: HPRs should support people with RMDs in self-management of their condition. This encompasses selecting and applying the appropriate behavioural approaches and techniques to optimise their health and well-being (eg, engagement in physical activity, pain and fatigue management)

There are many studies providing evidence for HPRs' competences to support people with RMDs in self-management of their condition, including the making of lifestyle and behavioural changes. $^{3} 491315$ 18-20 23-25 This support encompasses selecting and applying the appropriate cognitive and behavioural approaches and techniques to optimise their health and wellbeing (eg, engagement in physical activity, pain and fatigue management). The literature suggests that HPRs should be able to apply different techniques, like motivational interviewing, cognitive or behavioural approaches or other techniques. ${ }^{415} 1923$

Recommendation 10: HPRs should be able to select and apply outcome measures for people with RMDs, as appropriate, to evaluate the effectiveness of their interventions

HPRs should have the ability to select and apply outcome measures reflecting the objectives of their interventions for people with RMDs, to evaluate their effectiveness. ${ }^{34927}$

\section{Research and educational agendas}

The TF group proposed a research agenda (box 1) reflecting potential topics for future research and an educational agenda (box 2) identifying gaps in education for HPRs.

\section{DISCUSSION}

These are the first EULAR recommendations for the generic core competences of HPRs. Three OAP and ten recommendations were formulated and provide a basis for harmonising core competences of HPRs across countries. Ultimately, their implementation is expected to lead to improved patient care.

Sets of required competences HPRs of multiple professions have in common have been developed at the national level, ${ }^{349}$ with one set specifically for HPRs who act as a first point of contact. ${ }^{4}$ However, a set of core competences HPRs of multiple professions have in common was lacking at a European level, representing an unmet need. Following the European harmonisation of the competences of rheumatologists ${ }^{26}$ an international approach to HPRs' competences is important to reduce the variation in the quality of care for people with RMDs across countries. The proposed recommendations can

\section{Box 1 Research agenda}

- To further evaluate the patient perspective on the competences of health professionalsin rheumatology (HPRs).

- To refine HPRs' competences regarding the monitoring and improvement of the quality of their practice.

- To define the requirements for HPRs to improve and maintain their competences and explore the existence of human and financial resources to accomplish continuous education.

- To explore the desired competences of HPRs regarding the understanding and evaluation of the economic aspects of care for people with rheumatic and musculoskeletal diseases (RMDs)

- To define, in addition to generic core competences, disciplinespecific competences, related to each of the HPRs' unique role in the multidisciplinary team.

- To explore the role of HPRs in communities of practice for the delivery of seamless, integrated, patient-centred care for people with RMDs across Europe.

- To evaluate the involvement of HPRs in rheumatology research across countries and identify potential barriers and facilitators to research contribution.

inform the content of an international curriculum for HPRs, but can also be used in the development and/or optimisation of national postgraduate educational offerings.

The contents of the set of recommendations is largely in line with that of recently developed sets from the $\mathrm{UK}^{3}{ }^{4}$ and set from the Netherlands. ${ }^{9}$ Differences are that the UK set was specifically developed for health professionals with a role as first point of contact for adults presenting with undiagnosed musculoskeletal conditions, ${ }^{4}$ whereas the Dutch set aimed to describe discipline-specific rather than common competencies. ${ }^{9}$ Overall, the EULAR recommendations are less detailed than both the UK and Dutch sets, warranting the need for further elaboration. This should be done in close collaboration with national organisations to take into account the different roles and responsibilities of HPRs in different countries.

In general, the generic competences as described in the literature addressing HPRs of multiple professions were confirmed in

\section{Box 2 Educational agenda}

- To evaluate barriers and facilitators for the implementation of the generic core competences in various European countries, taking into account cultural, social and other differences.

- To review the current learning aims and curricula of health professional in rheumatology (HPR)-specific or interprofessional education at the postgraduate level across countries and use the formulated competences to enhance or create postgraduate education for HPRs, where appropriate.

- To confirm the validity and feasibility of the proposed set of generic competences for HPRs other than nurses, physical therapists or occupational therapists.

- To explore, enhance and promote the recognition of HPRs' specialist skills across countries.

- To develop educational offerings to increase HPRs' competences to support people with rheumatic and musculoskeletal diseases regarding self-management of pain, fatigue and the achievement or maintenance of a healthy lifestyle. 
the literature on competences of either nurses, PTs or OTs. Some details were stressed more in the literature on one profession than another, such as, for example, the importance of the assessment of sexual health, ${ }^{36486575}$ cardiovascular risk ${ }^{53}$ or nutritional and dietary status ${ }^{66}$ in the nurses' literature. It should be noted in this respect that for some competences it is clear that they are applicable to HPRs of multiple professions, whereas for others the assignment to one profession or the other is ambiguous. We have used one of the papers describing generic core competences by profession ${ }^{9}$ to support the distinction between competences HPRs from multiple professions have in common and profession specific competences, but that study is from only one country. It would thus be worthwhile to take this discussion into account with the proposed evaluation of barriers and facilitators for the implementation of the generic core competences in various European countries, as formulated for one of the topics of the research agenda. The proposed educational and research agendas also include aspects of a kind of reality check regarding the proposed competences, an example being a review of how competences addressed in current and envisioned postgraduate education relate to the recommendations. Moreover, proposals on how to change current settings based on an analysis of barriers and facilitators for the implementation of the recommendations must be made.

The competent HPRs are expected to function in close collaboration with competent rheumatologists in order to provide appropriate healthcare for people with RMDs as well as participate in joint professional and educational developments. The competence-based training requirements for specialty of rheumatology, oriented towards the professional behaviour within the rheumatologist's competences have been proposed on the European level. ${ }^{27}$ The main overlap between the rheumatologists' and HPRs' competences exists in the area of working and communicating in the multidisciplinary team (recommendation 3).

The work of this TF identified a potential challenge in formulating recommendations which are based primarily on qualitative research. Qualitative research is often underestimated, but of high relevance and importance in the study of specific topics. However, the lack of explicit frameworks or guidelines on how to best use qualitative evidence, including the formulation of recommendations, represents a challenge. As part of this work, we have identified a four-level hierarchy of evidence-for-practice in qualitative research studies, ${ }^{11}$ which along with a meticulous assessment of the quality of papers identified from the SLR, provided good ground and informed decisions on the assignment of LoE and SoR for each recommendation. Work is currently underway by the TF methodologists, to further inform the process and provide a guide on the use of appropriate tools for the assignment of LoE and SoR for recommendations stemming primarily from qualitative research. We trust that this will standardise as well as encourage the appropriate use of qualitative research to inform EULAR recommendations in the future.

In conclusion, these recommendations aim to provide a framework for the generic core competences of nurses, PTs and OTs for postgraduate education at international and national level. Efforts will be made towards their implementation through dissemination across national societies, relevant websites and presentation of this work at key international and national conferences. It is advised that variation in healthcare systems and professions across countries is considered. For this purpose, the recommendations will be shared with a larger group of HPRs, clinicians, patients and service providers, for wider consensus and external validation.

\section{Author affiliations}

'Orthopaedics, Rehabilitation and Physical Therapy, J11, Leiden University Medical Center, Leiden, The Netherlands

${ }^{2}$ Amsterdam Rehabilitation Research Center, Reade, Amsterdam, The Netherlands

${ }^{3}$ Inflammation Biology, King's College London, London, UK

${ }^{4}$ Institute of Infection, Immunity and Inflammation, University of Glasgow School of Medicine, Glasgow, UK

${ }^{5}$ Scienze Cliniche e Biologiche, Università degli Studi di Torino, Turin, Italy

${ }^{6}$ EULAR, Zurich, Switzerland

${ }^{7}$ Clinical Education, King's College London, London, UK

${ }^{8}$ Standing Committee of People with Arthritis/Rheumatism in Europe (PARE), EULAR, Zurich, Switzerland

${ }^{9}$ Rheumatology, Hospital Garcia de Orta, Almada, Portugal

${ }^{10}$ Divsion of Clinical Immunology and Rheumatology, University of Zagreb School of Medicine, Zagreb, Croatia

${ }^{11}$ Nursery and Midwifery, University of the West of England Bristol, Bristol, UK

${ }^{12}$ Department of Regional Health Research, University of Southern Denmark, Odense, Denmark

${ }^{13}$ Danish Hospital for Rheumatic Diseases, Graasten, Denmark

${ }^{14}$ Regional Health Research, University of Salford, Salford, UK

${ }^{15}$ Rheumatology Outpatients, Mid Cheshire Hospitals NHS Foundation Trust, Crewe, UK

${ }^{16}$ Section for Outcomes Research, Centre for Medical Statistics, Informatics, and Intelligent Systems, Medical University of Vienna, Vienna, Austria

${ }^{17}$ Occupational Therapy, University of Applied Sciences FH Campus Wien, Wien, Austria

${ }^{18}$ III. Medical Clinic, Dept of Oncology, Hematology and Rheumatology, University Hospital Bonn, Bonn, Germany

${ }^{19}$ Center of Medical Rehabilitation, Institute of Rheumatology, Praha, Czech Republic

${ }^{20}$ Rheumatology, Diakonhjemmet Hospital, Oslo, Norway

${ }^{21}$ Department of Neuroscience, Rehabilitation, Ophthalmology, Genetics, Maternal and Child Health, University of Genova, Genova, Italy

Acknowledgements We thank J W Schoones, Walaeus Library, Leiden University Medical Center, the Netherlands, for his assistance with the literature search in the electronic databases. We also thank Dr H Lempp, medical sociologist from King's College London, London, UK, for her expert advice in the methodological quality assessment of qualitative research studies and considerations around hierarchical level of evidence.

Contributors All authors have actively contributed to the work and meet the criteria for authorship.

Funding The task force would like to thank EULAR for financial support of this work.

Competing interests None declared.

Patient consent for publication Not required.

Provenance and peer review Not commissioned; externally peer reviewed.

\section{ORCID iDs}

Elena Nikiphorou http://orcid.org/0000-0001-6847-3726

George E Fragoulis http://orcid.org/0000-0003-4932-7023

Lurdes Barbosa http://orcid.org/0000-0001-7010-5228

Mwidimi Ndosi http://orcid.org/0000-0002-7764-3173

Jette Primdahl http://orcid.org/0000-0002-1049-4150

Valentin Sebastian Schäfer http://orcid. org/0000-0002-6591-5936

Hana Smucrova http://orcid.org/0000-0001-8614-4934

Theodora P M Vliet Vlieland http://orcid.org/0000-0001-6322-3859

\section{REFERENCES}

1. Vliet Vlieland TPM, van den Ende CHM, Alliot-Launois F, et al. Educational needs of health professionals working in rheumatology in Europe. RMD Open 2016:2:e000337.

2. UEMS. Training requirements for the specialty of rheumatology: European standards of postgraduate medical specialist training, 2014. Available: https://www.uems.eu/_ data/assets/pdf_file/0005/44438/UEMS-2014.21-European-Training-RequirementsRheumatology-.pdf [Accessed Jan 2019].

3. Erwin J, Edwards K, Woolf A, et al. Better arthritis care: what training do communitybased health professionals need to improve their care of people with arthritis? A Delphi study. Musculoskeletal Care 2018;16:48-59.

4. Health Education England, NHS England and Skills for Health 2018. Musculoskeletal core capabilities framework for first point of contact practitioners. NHS England Publications Gateway Reference: 082896, 2018.

5. van der Heijde D, Aletaha D, Carmona L, et al. Update of the EULAR standardised operating procedures for EULAR-endorsed recommendations. Ann Rheum Dis 2014:2014:8-13.

6. Harden A, Brunton G, Fletcher A, et al. Teenage pregnancy and social disadvantage: systematic review integrating controlled trials and qualitative studies. BMJ 2009;339. 
7. Pluye $\mathrm{P}$, Gagnon M-P, Griffiths F, et al. A scoring system for appraising mixed methods research, and concomitantly appraising qualitative, quantitative and mixed methods primary studies in mixed studies reviews. Int J Nurs Stud 2009;46:529-46.

8. Shea BJ, Reeves BC, Wells G, et al. AMSTAR 2: a critical appraisal tool for systematic reviews that include randomised or non-randomised studies of healthcare interventions, or both. BMJ 2017;358.

9. Hurkmans EJ, Verhoef J, Arts-Sanders MA, et al. Competenties en scholingsbehoeften van health professionals werkzaam in de reumatologie. Nederlands Tijdschrift voor Reumatologie 2013:56-63.

10. Centre for Evidence-Based Medicine. Oxford centre for evidence-based medicine levels of evidence 2009, 2009. Available: http://www.cebm.net/?0=1116 [Accessed Jan 2019].

11. Daly J, Willis K, Small R, et al. A hierarchy of evidence for assessing qualitative health research. J Clin Epidemiol 2007;60:43-9.

12. Bergsten U, Bergman S, Fridlund B, et al. "Delivering knowledge and advice": Healthcare providers' experiences of their interaction with patients' management of rheumatoid arthritis. Int I Qual Stud Health Well-being 2011;6:8473.

13. Brodin N, Hurkmans E, DiMatteo L, et al. Promotion of health-enhancing physical activity in rheumatoid arthritis: a comparative study on healthcare providers in Italy, the Netherlands and Sweden. Rheumatol Int 2015:35:1665-73.

14. Darlow B, Fullen BM, Dean $S$, et al. The association between health care professional attitudes and beliefs and the attitudes and beliefs, clinical management, and outcomes of patients with low back pain: a systematic review. Eur J Pain 2012;16:3-17.

15. Dures E, Hewlett S, Ambler N, et al. Rheumatology clinicians' experiences of brief training and implementation of skills to support patient self-management. BMC Musculoskelet Disord 2014;15:108.

16. Erwin J, Edwards K, Woolf A, et al. Better arthritis care: patients' expectations and priorities, the competencies that community-based health professionals need to improve their care of people with arthritis? Musculoskeletal Care 2018;16:60-6.

17. Helland $Y$, Garratt A, Kjeken I, et al. Current practice and barriers to the management of sexual issues in rheumatology: results of a survey of health professionals. Scand J Rheumatol 2013:42:20-6.

18. Hurkmans EJ, de Gucht V, Maes $S$, et al. Promoting physical activity in patients with rheumatoid arthritis: rheumatologists' and health professionals' practice and educational needs. Clin Rheumatol 2011:30:1603-9.

19. Larkin L, Gallagher S, Fraser A, et al. If a joint is hot it's not the time: health professionals' views on developing an intervention to promote physical activity in rheumatoid arthritis. Disabil Rehabil 2017;39:1106-13.

20. Lillie K, Ryan S, Adams J. The educational needs of nurses and allied healthcare professionals caring for people with arthritis: results from a cross-sectional survey. Musculoskeletal Care 2013;11:93-8.

21. Lundon K, Shupak R, Reeves S, et al. The advanced clinician practitioner in arthritis care program: an interprofessional model for transfer of knowledge for advanced practice practitioners. J Interprof Care 2009;23:198-200.

22. Maycock JA. Role of health professionals in patient education. Ann Rheum Dis 1991;50(Suppl 3):429-34.

23. Moe RH, Fongen C, Sand-Svartrud A. Professional-specific and interdisciplinary core competence in Norwegian rheumatology, 2018.

24. Taal E, Bobietinska E, Lloyd J, et al. Successfully living with chronic arthritis. Clin Rheumatol 2006:25:189-97.

25. Willems LM, Redmond AC, Stamm TA, et al. Content of non-pharmacological care for systemic sclerosis and educational needs of European health professionals: a EUSHNet survey. Clin Exp Rheumatol 2015;33:S153-9.

26. Woolf AD. Health care services for those with musculoskeletal conditions: a rheumatology service; recommendations of the UEMS section of Rheumatology/ European board of rheumatology 2006, 2006.

27. Zangi HA, Ndosi M, Adams J, et al. EULAR recommendations for patient education for people with inflammatory arthritis. Ann Rheum Dis 2015;74:954-62.

28. (ARHP) AoRHP. Role of the clinical nurse specialist in the management of rheumatic disease. Available: www.rheumatology.org [Accessed Jan 2019].

29. Antonelli MC, Starz TW. Assessing for risk and progression of osteoarthritis: the nurse's role. Am J Nurs 2012;112(3 Suppl 1):S26-S31.

30. Arvidsson B, Jacobsson L, Petersson IF. Rheumatology care in Sweden - the role of the nurse. Musculoskeletal Care 2003;1:81-3.

31. Arvidsson SB, Petersson A, Nilsson I, et al. A nurse-led rheumatology clinic's impact on empowering patients with rheumatoid arthritis: a qualitative study. Nurs Health $\mathrm{Sci}$ 2006;8:133-9.

32. Beauvais C, Gossec L, Mulliez A, et al. FRI0622-HPR What Competencies for Rheumatology Nurses? Results of a Multicentric Survey Among Health Professionals and Nurses in France. Ann Rheum Dis 2015;74(Suppl 2):1326.3-7.

33 Beauvais C, Gossec L, Mulliez A, et al. SAT0627-HPR Educational needs of French rheumatology nurses are not limited to inflammatory arthritis management. Results of the multicentric 'caire' study. Ann Rheum Dis 2016;75:1290.

34. Burbage G. Detecting and managing rheumatoid arthritis. Practice Nursing 2008:19:26-30

35. Candelas G, Villaverde V, García S, et al. Benefit of health education by a training nurse in patients with axial and/or peripheral psoriatic arthritis: a systematic literature review. Rheumatol Int 2016;36:1493-506.
36. Cornell P. Management of patients with rheumatoid arthritis. Nurs Stand 2007:22:51-7.

37. Cottrell JED, Jonas $M$, Bergsten $U$, et al. The nurse's role in addressing unmet treatment and management needs of patients with rheumatoid arthritis: Delphi-based recommendations. Int J Nurs Know/ 2013;24:66-76.

38 Crofts P, D'Cruz D. Systemic lupus erythematosus. Part 2: the role of the nurse. Nurs Stand 1997:11:40-4.

39. Daly M. Osteoarthritis: diagnosis, treatment and the nurse's role. World of Irish Nursing and Midwifery 2012;20:39-40.

40. Dziedzic KS, Healey EL, Main CJ. Implementing the NICE osteoarthritis guidelines in primary care: a role for practice nurses. Musculoskeletal Care 2013;11:1-2.

41. Goh L, Samanta J, Samanta A. Rheumatology nurse practitioners' perceptions of their role. Musculoskeletal Care 2006:4:88-100.

42. Grahame R, West J. The role of the rheumatology nurse practitioner in primary care: an experiment in the further education of the practice nurse. Rheumatology 1996;35:581-8.

43. Hall AM. A nurse-led service to provide information on osteoarthritis. Nurs Times 2005;101:38-9.

44. Healey EL, Main CJ, Ryan S, et al. A nurse-led clinic for patients consulting with osteoarthritis in general practice: development and impact of training in a cluster randomised controlled trial. BMC Fam Pract 2016;17:173.

45. Hill J. The expanding role of the nurse in rheumatology. Br J Rheumatol 1997:36:410-2.

46. Juhola H, Kukkurainen ML, Suominen T. Rheumatology nurses' work-related empowerment. Musculoskeletal Care 2007;5:91-7.

47. Mäkeläinen $\mathrm{P}$, Vehviläinen-Julkunen $\mathrm{K}$, Pietilä A-M. Rheumatoid arthritis patients' education - contents and methods. J Clin Nurs 2007;16:258-67.

48. Newman AM. Arthritis and sexuality. Nurs Clin N Am 2007:42:621-30.

49. Nolan M, Nolan J. Arthritis and rehabilitation: developments in the nurse's role. British Journal of Therapy and Rehabilitation 1998;5:608-15.

50. O'Donovan J. Managing rheumatoid arthritis: the role of nurse in a multidisciplinary team. Primary Health Care 2001;14:30-2.

51. Oliver $\mathrm{S}$. Understanding the needs of older people with rheumatoid arthritis: the role of the community nurse. Nurs Older People 2009;21:30-7.

52. Pointer W, Williams PL. The expanding role of the nurse in rheumatology. Rheumatology 1998;37:233

53. Primdahl J, Ferreira RJO, Garcia-Diaz S, et al. Nurses' role in cardiovascular risk assessment and management in people with inflammatory arthritis: A European perspective. Musculoskeletal Care 2016:14:133-51.

54. Repping-Wuts H, Hewlett $\mathrm{S}$, van Riel $\mathrm{P}$, et al. Fatigue in patients with rheumatoid arthritis: British and Dutch nurses' knowledge, attitudes and management. J Adv Nurs 2009;65:901-11.

55. Riley L, Harris C, McKay M, et al. The role of nurse practitioners in delivering rheumatology care and services. J Am Assoc Nurse Pract 2017;29:673-81.

56. Robbins L, Kulesa MG. The state of the science in the prevention and management of osteoarthritis: experts recommend ways to increase nurses awareness and knowledge of osteoarthritis. Hospital for Special Surgery 2012:8:151-8.

57. Ryan $\mathrm{S}$. The role of the nurse in the management of scleroderma. Nurs Stand 1996:10:39-42.

58. Ryan S. Defining the role of the specialist nurse. Nurs Stand 1996;10:27-9.

59. Ryan $S$, Hassell A, Thwaites $C$, et al. Exploring the perceived role and impact of the nurse consultant. Musculoskeletal Care 2006:4:167-73.

60. Ryan S, Browne A, Home D, et al. Benchmarking the nurse consultant role in rheumatology. Nursing Standard 2006;20:52-7.

61. Ryan S, Stevenson K, Hassell AB. Assessment of clinical nurse specialists in rheumatology using an OSCE. Musculoskeletal Care 2007;5:119-29.

62. Ryan S, Hassell A, Carpenter E. Characterizing the clinical practice and professional behaviour of rheumatology nurse specialists: a pilot study. Musculoskeletal Care 2010;8:136-42.

63. Ryan S, Packham JC, T Dawes P, et al. The impact of a nurse-led chronic musculoskeletal pain clinic on healthcare utilization. Musculoskeletal Care 2012;10:196-201.

64. Ryan S, McCabe CS, Adams J. The current knowledge and confidence of rheumatology nurses in providing advice on pain management. Musculoskeletal Care 2016:14:62-6

65. Schoofs N. Caring for women living with Sjögren's syndrome. J Obstet Gynecol Neonatal Nurs 2003;32:589-93.

66. Swanson KI, Pfenning S. The nurse practitioner's role in the management of rheumatoid arthritis. J Nurse Pract 2011:7:858-70.

67. van Eijk-Hustings Y, van Tubergen A, Boström C, et al. EULAR recommendations for the role of the nurse in the management of chronic inflammatory arthritis: table 1. Ann Rheum Dis 2012;71:13-19.

68. Walker J. Rheumatoid arthritis: role of the nurse and multidisciplinary team. Br J Nurs 2012:21:334-9.

69. Watts RA, Mooney J, Barton G, et al. The outcome and cost-effectiveness of nurseled care in the community for people with rheumatoid arthritis: a non-randomised pragmatic study. BMJ Open 2015;5:e007696. 
70. Wheeler T. Systemic lupus erythematosus: the basics of nursing care. Br J Nurs 2010;19:249-53.

71. (ARHP) AoRHP. What does the physical therapist do? Available: www.rheumatology. org [Accessed Jan 2019].

72. Andersson SF, Bergman S, Henriksson EW, et al. Arthritis management in primary care - A study of physiotherapists' current practice, educational needs and adherence to national guidelines. Musculoskeletal Care 2017;15:333-40.

73. Briggs AM, Fary RE, Slater $\mathrm{H}$, et al. Disease-Specific knowledge and clinical skills required by community-based physiotherapists to co-manage patients with rheumatoid arthritis. Arthritis Care Res 2012;64:1514-26.

74. Grimmer K, Kumar S, Gilbert A, et al. Non-Steroidal anti-inflammatory drugs (NSAIDs): physiotherapists' use, knowledge and attitudes. Aust J Physiother 2002;48:82-92.

75. Josefsson KA, Gard G. Sexual health in patients with rheumatoid arthritis: experiences, needs and communication with health care professionals. Musculoskeletal Care 2012;10:76-89

76. Li LC, Hurkmans EJ, Sayre EC, et al. Continuing professional development is associated with increasing physical therapists' roles in arthritis management in Canada and the Netherlands. Phys Ther 2010;90:629-42.

77. Mihai C, Van der Linden S, De Bie R, et al. Experts' beliefs on physiotherapy for patients with ankylosing spondylitis and assessment of their knowledge on published evidence in the field. Results of a questionnaire among international ASAS members. Eur J Phys Rehabil Med 2005;41.

78. Page RL, Scherer SA, Smith MB. Physical therapists' knowledge, attitudes, and professional use of nonprescription analgesics. Am J Health Syst Pharm 2005;62:1440-1.
79. Papi E, Murtagh GM, McGregor AH. Wearable technologies in osteoarthritis: a qualitative study of clinicians' preferences. BMJ Open 2016;6:e009544.

80. Spitaels D, Hermens R, Van Assche D, et al. Are physiotherapists adhering to quality indicators for the management of knee osteoarthritis? an observational study. Musculoskelet Sci Pract 2017;27:112-23.

81. Verhoef J, Oosterveld FGJ, Hoekman R, et al. A system of networks and continuing education for physical therapists in rheumatology: a feasibility study. Int I Integr Care 2004;4.

82. Westby MD, Klemm A, Li LC, et al. Emerging role of quality indicators in physical therapist practice and health service delivery. Phys Ther 2016;96:90-100.

83. (ARHP) AoRHP. What does the occupational therapist do? Available: www. rheumatology.org [Accessed Jan 2019].

84. Dubouloz C-J, Vallerand J, Laporte D, et al. Occupational performance modification and personal change among clients receiving rehabilitation services for rheumatoid arthritis. Aust Occup Ther J 2008:55:30-8.

85. Hammond A. What is the role of the occupational therapist? Best Pract Res Clin Rheumatol 2004;18:491-505.

86. Niedermann $\mathrm{K}$, Hammond A, Forster A, et al. Perceived benefits and barriers to joint protection among people with rheumatoid arthritis and occupational therapists. A mixed methods study. Musculoskeletal Care 2010;8:143-56

87. European Board of Rheumatology (a section of UEMS). The European rheumatology curriculum framework, 2008. Available: https:/www.eular.org/myUploadData/files/ UEMS_European_Curriculum_2008.pdf [Accessed Jan 2019]. 